\title{
Research on the Effect of Chinese Margin Trading on Market Risk: Based on GJR Model and Filtered Historical Simulation
}

\author{
Lan-Ya Ma ${ }^{1}, \mathrm{Zi}-\mathrm{Yu} \mathrm{Li}^{1}$ \\ ${ }^{1}$ Finance Department of International Business School, Jinan University, Zhuhai, China \\ Correspondence: Zi-Yu Li, Finance Department of International Business School, Jinan University, Qianshan Road \\ 206\#, Zhuhai City, Guangdong Province, Post No.519070, China.
}

Received: March 30, 2017

Accepted: May 2, $2017 \quad$ Available online: June 15, 2017

doi:10.11114/aef.v4i4.2315

URL: https://doi.org/10.11114/aef.v4i4.2315

\begin{abstract}
In this paper, we address the issue that the financial institutes need to identify the risk of margin trading, and we analyze the volatility and value at risk of China's Shanghai-Shenzhen 300 Index before and since the inception of margin trading policy. We first analyze the statistical attributes of the logarithmic return series. Then we build the GJR-GARCH to model the difference of volatility and leverage effect of the two sample time series. After that, we calculate the dynamic value at risk based on the parametric method. Moreover, we apply the filtered historical simulation with the help of Bootstrap technique to obtain the pathway of return and finally calculate the value at risk under the two circumstances. In the end, we propose some reasonable policies to financial risk management department.
\end{abstract}

Keywords: volatility, value at risk, GJR model, leverage effect, FHS

\section{Introduction}

\subsection{Background Description}

Since the reform and opening up, China's capital market has been continuously developing towards to a market-oriented one. China's margin trading started later than that in Europe, United States, Hong Kong and other more developed financial markets. Since the beginning of 2010, the underlying stocks pool has expanded four times from the initial 90 stocks to more than 900. At the same time, the size of margin trading grew rapidly (Figure 1). However, the margin trading is mainly buying, which also reflects the immaturity of China's securities market. From 2014 to 2015, China's stock market entered into the bull market (Figure 2) where investors' enthusiasm ran high and margin trading volume increased at a fast pace. However, then the stock market crashed, the stock price and the market index fell sharply. Meanwhile the market volatility increased, investors were at higher risks. Then the market trading volume as well as margin trading volume shrank. As a consequence, the regulatory authorities imposed restrictions on the margin trading. Industry and academia began to rethink more about the impact of the financial services on the stock market and the risk behind the problem.

\subsection{Relevant Scholarship}

Miller (1977) pointed out that in the existence of short selling restrictions, the stock investors not optimistic about the future will withdraw from the market, while optimistic investors continue to invest in the market. At this time the market can only reflect the judgment of optimistic investors, so there will be overvalued share price phenomenon; Detemple and Sheldon (1991) introduced the incomplete market environment to the risk model based on option contract and divided the securities assets into the stock and risk-free bonds, he believed that the emergence of financial derivatives has great impact on the stock market, not only to raise the stock price, but also can reduce the impact of credit transaction fluctuations on the price earnings ratio.

Anchada Charoenrook and Hazem Daouk (2003) used the exchange rate as a measure of liquidity indicators to study 88 emerging markets and 23 developed markets. The results of Clearly, there is volatility trading mechanism of stock market returns lower in emerging markets than prohibit securities transactions, on the contrary, the stability of the developed securities market is higher than that of the emerging securities market; Ernan, Haruvy and Charles $\mathrm{N}$ Noussair (2006) study showed that short selling could prevent the price exceeds the fundamental value of the effect, but did not solve the problem that the short market price cannot reflect the basic value, may make the market price lower than the basic value; Wang Min, Liao Shiguang (2008) used the margin trading data of Taiwan stock market, research 
on the impact of margin trading on the whole market based on Granger Causality Test from market liquidity and volatility; Ekkehart Boehmer and Julie $\mathrm{Wu}$ (2009) presented that short selling transaction improves the information efficiency of price by the experimental evidence, and through the further study in 2012 to further conclude that when the more active players when the more accurate stock pricing.

Jia Mingqi, Zhao Liang (2012) on the balance of margin and the Shanghai Composite Index monthly standard deviation of the Johansen cointegration test, determined the two have long-term cointegration relationship; Pedro A.C Saffi and Kari Sigurdsson (2011) pointed out that the stock pricing efficiency and profit distribution were influenced by short selling and constraint stock under strict short sales constraints had low pricing efficiency; Alessandro Beber and Marco Pagano (2013) obtained that short selling restrictions have a negative impact on liquidity, price discovery, and stock prices by studying the various short selling policies made by most of the world's regulators during the 2007-2009 financial crisis; Feng Yumei, Chen Xuan et al. (2001) used vector autoregressive (VAR) to test the impact of the margin trading mechanism on the volatility of China's stock market during the pilot period. The VAR model of margin trading and stock market volatility was established to examine the impact of the margin on the volatility of the stock market before and after the transfer.

\subsection{Research Design}

In summary, domestic and foreign scholars studied the efficiency of the stock market pricing, volatility and risk management measures, etc. However, few of them comprehensively studied the impact that margin trading have on market risks from a dynamic perspective, and most data they used were before the 2015 stock market crash, which did not cover the recent years.

Our main results are the following. Based on the CSI 300 index from 2005 to 2017, we modeled the volatility of the two sets of time series data divided at the time of 2010, when China's margin trading was first introduced, and then we calculated the dynamic value at risks of each set. Finally, we applied bootstrap resampling method to simulate the future return rate path of the CSI 300 index based on an improved historical simulation method.

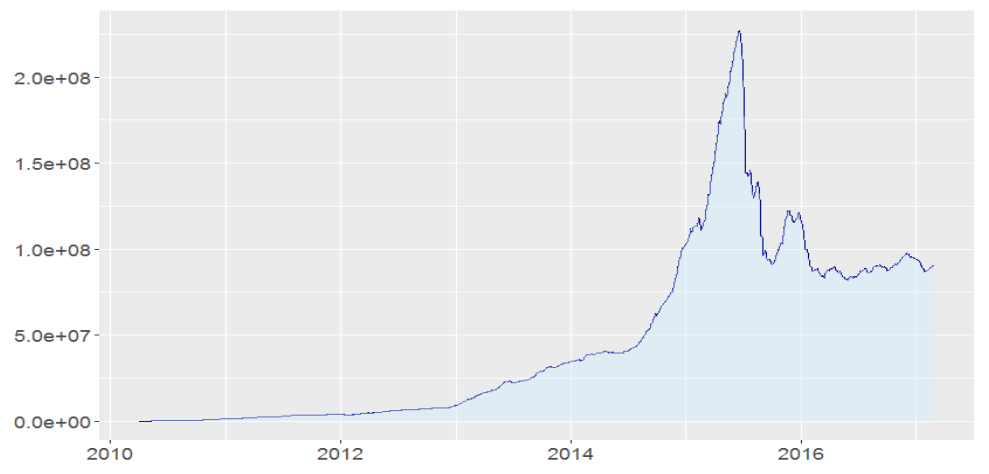

Figure 1. Margin balance changes

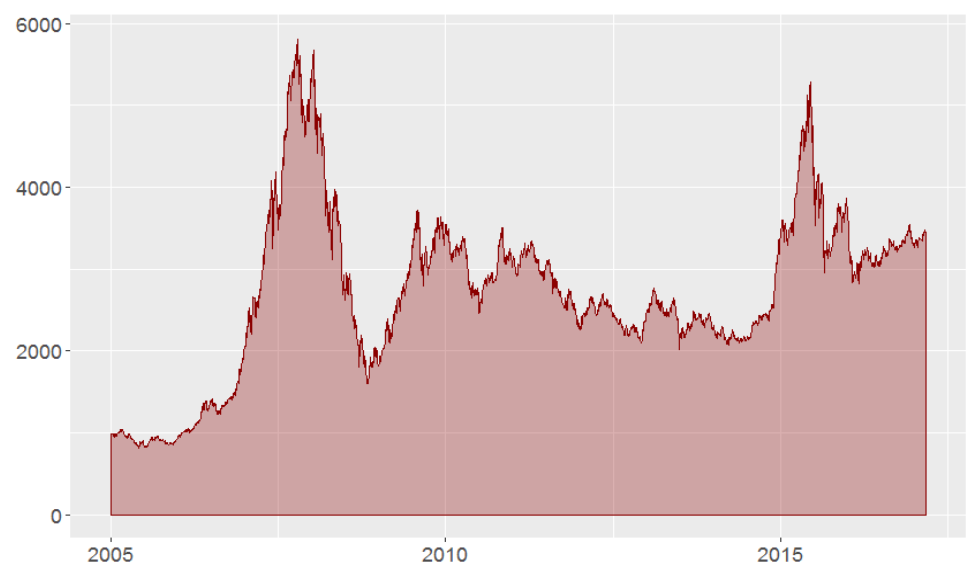

Figure 2. CSI 300 index trend

\section{Introduction to Theories and Models}

\subsection{GJR-GARCH Model}

GJR-GARCH is a variant of the GARCH model, which includes leverage item to characterize asymmetric fluctuations in financial time series, which reflects a greater impact respond to negative information than the positive one. The GJR model is named by its authors Glosten, Jagannathan and Runkle. The GJR model is commonly shown as: 


$$
\begin{aligned}
y_{t} & =x_{t}^{\prime} \psi+u_{t}, u_{t} \sim N\left(0, \sigma_{t}^{2}\right) \\
\sigma_{t}^{2} & =\alpha_{0}+\sum_{i=1}^{p} \alpha_{i} u_{t-i}^{2}+\sum_{j=1}^{q} \beta_{j} \sigma_{t-j}^{2}+\sum_{j=1}^{q} \gamma_{j} D_{t-j} \sigma_{t-j}^{2}
\end{aligned}
$$

where $D_{t-1}$ is the dummy variable:

$$
\left\{\begin{array}{l}
D_{t-j}=0, u_{t-i} \geq 0 \\
D_{t-j}=1, u_{t-i}<0
\end{array}\right.
$$

So when $\gamma_{t}>0$, the negative shock has a greater impact than the positive shock on the conditional variance. Based on the GARCH model, the GJR-GARCH model takes the leverage effect into consideration as it introduces dummy variables to represent the impact of positive and negative shocks on $\sigma_{t}^{2}$.

\subsection{Calculation of VaR Based on GJR Model}

Value at risk (VaR) refers to the maximum expected loss of a financial asset or portfolio in a given confidence interval and holding period under normal market volatility. VaR is an important quantitative measure of market risk based on statistical analysis. Assume the value of assets held at the beginning of the period is $w_{0}$, the return rate of assets is $R$ with a mean value of $\mu$ and a variance of $\delta^{2}$; the holding period is $\Delta t$; the expected return rate of assets is $E(R)$, and the lowest return rate at the confidence level $\mathrm{C}$ is $R^{*}$. According to the definition, the VaR formula can be expressed as:

$$
\operatorname{VaR}=w_{0}\left[E(R)-R^{*}\right]
$$

If we assume that the asset return rate sequence $\left\{r_{t}\right\}$ is subject to a normal distribution, to obtain $R^{*}$ at a given confidence level, we need to find out the upper points $\alpha$ of the standard normal distribution which can achieve

$$
1-C=\int_{-\infty}^{-\alpha} \varphi(x) d w
$$

According to:

$$
-\alpha=\frac{R^{*}-\mu \Delta t}{\delta \sqrt{\Delta t}},
$$

We can obtain $R^{*}$ corresponding to the confidence level C:

$$
R^{*}=-\alpha \delta \sqrt{\Delta t}+\mu \Delta t
$$

Then we can obtain the variance covariance model as a general solution to VaR:

$$
\operatorname{VaR}=w_{0}\left(\mu \Delta t-R^{*}\right)=w_{0} \alpha \delta \sqrt{\Delta t}
$$

Although we have obtained the method of calculating the risk value through the above derivation, the assumption that return rate sequences are normally distributed are not always sound. In fact, large amount of empirical studies have proved that China's stock market return rate sequence has a "leptokurtosis" feature. Therefore, this paper uses the GJR-GARCH model to calculate the dynamic conditional variance $\sigma_{t}^{2}$, and thus we have :

where $P_{t-1}$ is the stock price index of the day before.

$$
V_{a}=P_{t-1} \alpha_{c} \sigma_{t}
$$

During the empirical study, we usually consider a variety of distributions, such as normal distribution, $t$ distribution, generalized error distribution (GED), etc. In this paper, we apply the normal distribution and t distribution to estimate the model respectively. We choose $t$ distribution because the tail of the $t$ distribution is fatter than the standard normal distribution, which is close to the real case.

\subsection{Bootstrap Re-sampling and Filtered Historical Simulation}

\section{(1) Bootstrap Resampling Method}

Bootstrap is a rather versatile tool that can be used to estimate standard errors, confidence intervals and deviations. With the assistance of the computer simulation, we can conduct statistical inference for a given sample. The basic idea is to use the sample data to compute the statistics and estimate the sample distribution without making any assumptions (nonparametric) for the model. The specific approach is to carry out random sampling from the original data, and the number of samples extracted equals to that of the original samples.

(2) Filtered Historical Simulation

The aforementioned VaR calculation of Shanghai-Shenzhen 300 Index requires the estimation of the distribution of the return rates. Whichever form is picked, the accuracy may be unsatisfactory in reality. Barone-Adesi, G., K. 
Giannopoulos and other scholars proposed a new nonparametric historical simulation method "Filtered Historical Simulation", a historical simulation with filtering, which overcomes the shortcomings of traditional historical simulation methods. Traditional historical simulations are no longer valid for longer periods of time, since a longer time sequence should include extreme conditions of the market, and scholars have demonstrated that historical simulations will underestimate market risk in extreme markets. FHS can be used not only to estimate the risk of individual assets but also to measure the risk of a portfolio.

In the simulation process, Filtered Historical Simulation does not need to presume parameters, and the specific steps are as follows:

Step1: From the above GJR-GARCH model, we obtain the residual sequence $\varepsilon_{t}$ of return rates, and standardize it as follows:

$$
e_{t}=\frac{\varepsilon_{t}}{\sqrt{h_{t}}}
$$

Step2: Denote the current time as T, and we apply bootstrap method to extract the independent identically distributed residuals from the samples as a random error of the return rate sequence on the first day. The asset price of $\mathrm{T}+1$ is obtained as:

$$
\begin{aligned}
& z_{t+1}=e^{*} \sqrt{h_{t+1}} \\
& p_{t+1}=p_{t}+p_{t}\left(\mu r_{t}+\theta z_{t}+z_{t+1}\right)
\end{aligned}
$$

Step3: Repeat step 2. Then the following sequence is generated iteratively. Similarly, we can also obtain the value of volatility via simulation:

$$
\begin{gathered}
h_{t}=\omega+\alpha\left(\varepsilon_{t-1}-\gamma\right)^{2}+\beta h_{t-1} \\
h_{t+i}=\left(\omega+\alpha\left(z_{t+i-1}-\gamma\right)^{2}+\beta h_{t+i-1}\right) i \geq 2
\end{gathered}
$$

In this paper, after obtaining the simulation return rate sequence, we can obtain the cumulative distribution function (CDF). Then, we can get the VaR at a certain confidence level.

\section{Empirical Analysis}

\subsection{Data Selection and Description}

Concerning that the initial underlying assets are mainly the large-capitalization stocks, while the Shanghai and Shenzhen 300 index reflects the comprehensive price changes of stocks with strong liquidity and large market value, we choose the Shanghai and Shenzhen 300 index before and after the introduction of margin trading for research, which ranges from January 1, 2005 to March 1, 2017, with a total of 2952 samples. Moreover, the time series before and after the introduction of margin trading are analyzed respectively. The two sets of data both compromise a bull market, a bear market as well as a volatile market, which is essential for our subsequent study. The data in this paper come from the CSMAR database.

\subsection{Descriptive Statistics}

In this paper, we transform the CSI300 into a logarithmic return series form (Figure 3), we can find that the return series fluctuates up and down and exhibits a fluctuating agglomeration effect:

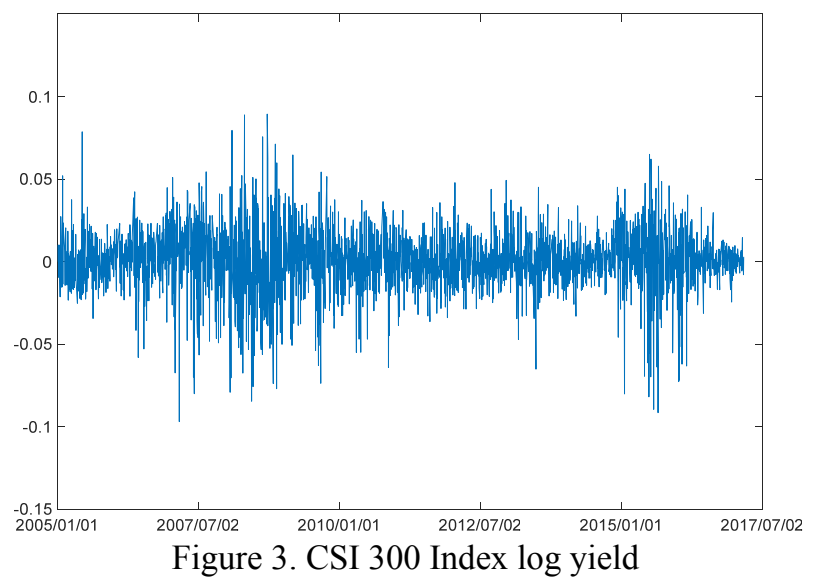

In order to avoid false regression, it is necessary to test the smoothness of the sequence in advance. In this paper, the 
logarithmic yield series of Shanghai and Shenzhen 300 index is tested by ADF unit root. The test results are as follows:

Table 1. ADF unit root test

\begin{tabular}{lcc} 
Augument D-F test Statistic & -52.7352 \\
& $1 \%$ & -3.9670 \\
Test Critical Values & $5 \%$ & -3.4140 \\
& $10 \%$ & -3.1282 \\
\hline
\end{tabular}

As can be seen from the results in Table 1, the ADF statistic values are significantly less than the critical values at each significant level, so the logarithmic yield series is considered to be stationary.

The results of descriptive statistics of the sequence are shown in Eviews8.0 as follows:

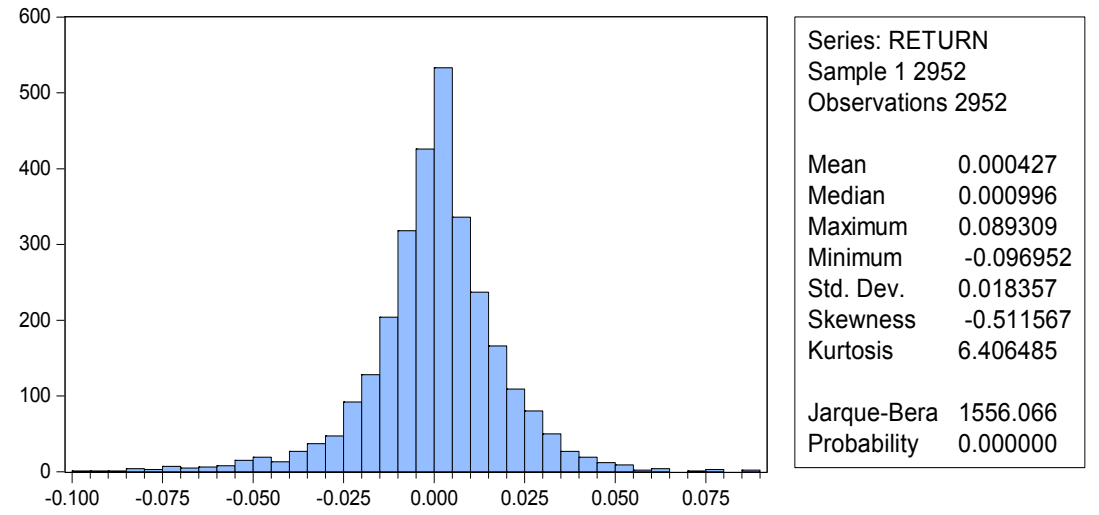

Figure 4. Exponential rate of return statistics

From the distribution histogram, the distribution of returns has the characteristics of "leptokurtosis and fat-Tail", which does not conform to the traditional Gaussian distribution hypothesis. The mean value is close to 0 , the skewness coefficient is less than 0 , and the kurtosis coefficient is lower than the kurtosis coefficient of the normal distribution. From the Jarque-Bera statistic (Figure 4) and the Kolmogorov-Smirnov nonparametric (Table 2) test, we can reject the null hypothesis that the distribution is a normal distribution.

Table 2. Kolmogorov-Smirnov test

\begin{tabular}{clc} 
& & \multicolumn{1}{c}{ VAR00001 } \\
\cline { 2 - 3 } Normal parameter & Normal parameter & 2952 \\
& standard deviation & 0.0004 \\
Most extreme & absolute value & 0.01836 \\
difference & Positive & 0.081 \\
& negative & 0.062 \\
Kolmogorov-Smirnov Z & -0.081 \\
Asymptotic significance (bilateral) & 4.381 \\
& & 0.000 \\
\hline
\end{tabular}

\subsection{Auto Correlation Analysis and ARCH-LM Test}

The logarithmic yield series of the CSI 300 index is obtained from the correlation function value, as shown in Figure 5. It can be seen that the relationship between the logarithmic yield series is not significant.

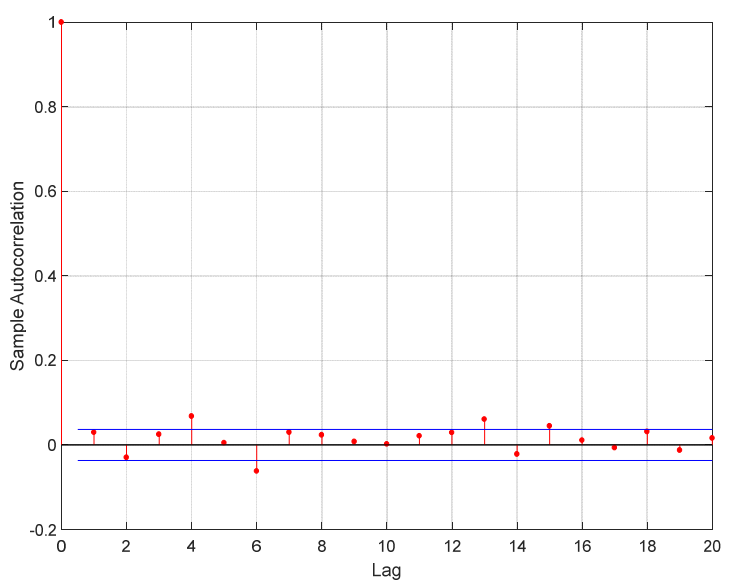

Figure 5. Sequence autocorrelation test 
From the yield sequence in Figure 3, we can deduce that the yield series has heteroskedasticity. The conditional heteroskedasticity test done to the CSI 300 index. The auto-regressive equation is:

$$
\ln r_{t}=\rho \ln r_{t-1}+\varepsilon_{t}
$$

The results ARCH-LM test of the residual sequence are shown in table 3 :

Table 3. ARCH effect test

\begin{tabular}{ccccc}
\hline & Hypothesis & Probability & LM Statistic & Critical Value \\
ARCH-LM & $\mathrm{h}=1$ & 0.00 & 79.8549 & 3.8415 \\
\hline
\end{tabular}

The null hypothesis is rejected under the significant level of 5\%. Thus there is an ARCH effect which meets the requirement of the GARCH model.

\subsection{Study the Sequence Fluctuation Characteristics Based on GJR}

The empirical study shows that the daily return series of Chinese stock market index has the characteristics of autocorrelation, fluctuation agglomeration and leverage effect. The GARCH model is designed to characterize the conditional variance of the time series to reflect the risk. The GARCH model can better capture the time series fluctuation agglomeration effect and also reflect a certain degree of spike posterior tail. Besides, the GJR-GARCH model can better capture the leverage effect.

The estimation equation for this paper is:

$$
\begin{aligned}
& y_{t}=x_{t}^{\prime} \psi+u_{t}, u_{t} \sim N\left(0, \sigma_{t}^{2}\right) \\
& \sigma_{t}^{2}=\alpha_{0}+\sum_{i=1}^{p} \alpha_{i} u_{t-i}^{2}+\sum_{j=1}^{q} \beta_{j} \sigma_{t-j}^{2}+\sum_{j=1}^{q} \gamma_{j} D_{t-j} \sigma_{t-j}^{2}
\end{aligned}
$$

Where:

$$
\left\{\begin{array}{l}
D_{t-j}=0, u_{t-i} \geq 0 \\
D_{t-j}=1, u_{t-i}<0
\end{array}\right.
$$

In this paper, the model is estimated under the assumption of normal distribution and $t$ distribution respectively. The estimation results are as follows:

Table 4. Model test

\begin{tabular}{ccc}
\hline T-Statistics & Gauss distribution hypothesis & T distribution hypothesis \\
GARCH(-1) & GJR $(1,1)$ & GJR $(1,1)$ \\
ARCH $(-1)$ & 102.792 & 90.325 \\
Leverage(-1) & 5.153 & 3.828 \\
DoF & 1.478 & 0.595 \\
AIC & - & 7.779 \\
BIC & -9695.0 & -9825.5 \\
\hline
\end{tabular}

From the test results of Table 4, under the assumption of $t$ distribution, the Akashi information criterion and Bayesian information criterion are higher than the Gaussian distribution hypothesis, so we use the t-distribution hypothesis.

The pre-launch of the margin policy is estimated as follows:

$$
\left\{\begin{array}{l}
\ln r_{t}=0.0019+0.0264 \ln r_{t-1}+\varepsilon_{t} \\
\sigma_{t}^{2}=0.9223 \sigma_{t-1}^{2}+0.0655 \varepsilon_{t-1}^{2}+0.0144 D_{t-1} \varepsilon_{t-1}^{2} \\
z_{t}=\varepsilon_{t} / \sigma_{t} \sim t(5)
\end{array}\right.
$$

After the introduction of margin trading policy, the estimation is as follows:

$$
\left\{\begin{array}{l}
\ln r_{t}=0.00027-0.00086 \ln r_{t-1}+\varepsilon_{t} \\
\sigma_{t}=0.943 \sigma_{t-1}^{2}+0.0504 \varepsilon_{t-1}^{2}+0.0077 D_{t-1} \varepsilon_{t-1}^{2} \\
z_{t}=\varepsilon_{t} / \sigma_{t} \sim t(4)
\end{array}\right.
$$

According to the estimated results, we can conclude that after the introduction of margin trading, leverage and asymmetric weaken. Then the conditional variance series is obtained by GJR-GARCH model: 


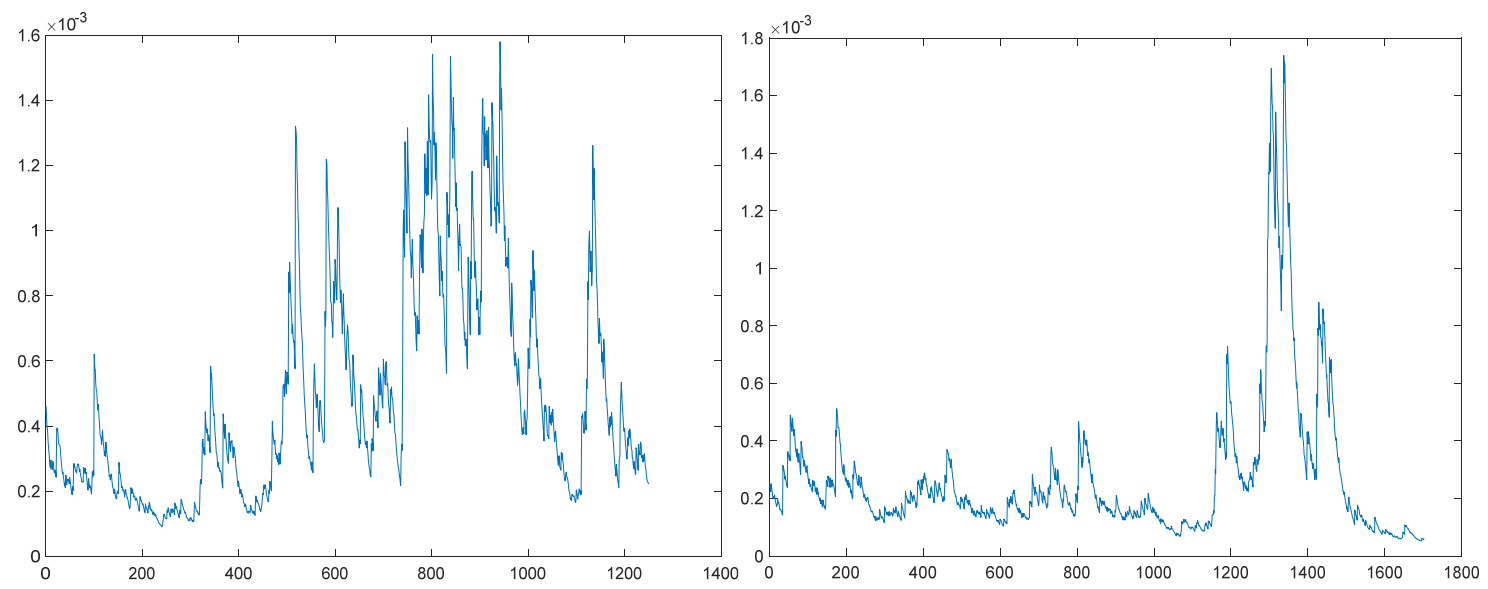

Figure 6. Changes in conditional variance before and after the introduction of Margin trading

We can get the return and risk (standard deviation) distribution (Figure 7), which can be found that the volatility of the market is reduced to some extent.

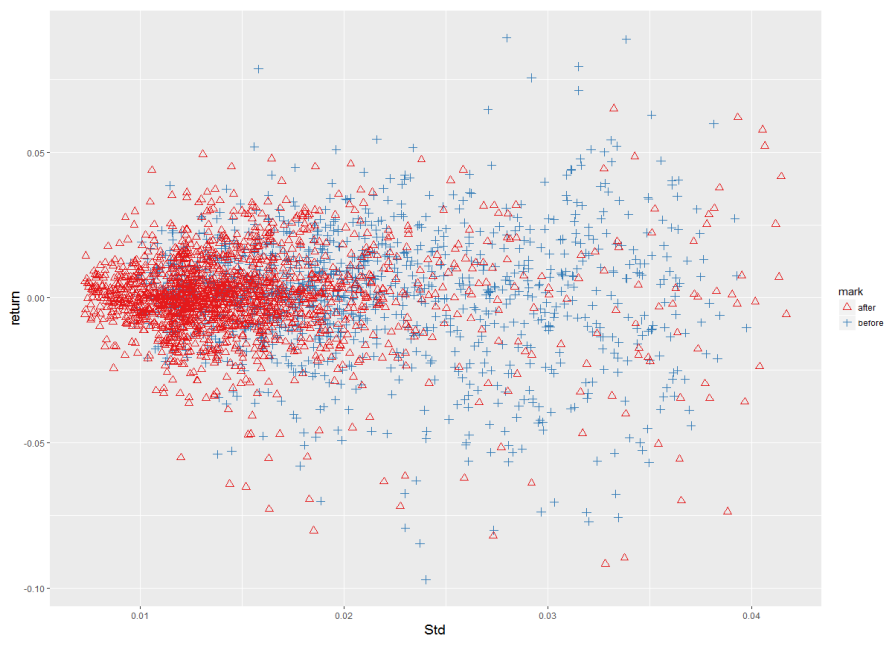

Figure 7. Risks and benefits before and after the introduction of margin trading

3.5 Measuring the VaR

Using the previous VaR formula:

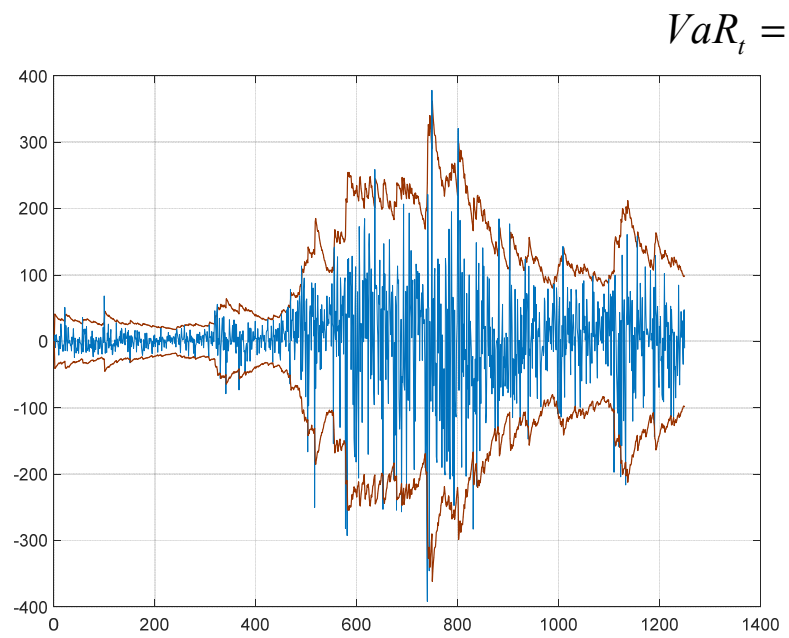

$=P_{t-1} \alpha_{c} \sigma_{t}$

Figure 8. Dynamic VaR estimation before and after the introduction of margin trading

The dynamic VaR of the CSI 300 index before and after the two flows are compared accordingly in Figure 8, and it is found that the VaR "wrap" the return series, which indicates that the VaR calculated in this paper can measure the risk effectively. 
We can also conclude that in the extreme conditions of the market, the value at risk of the two sequences is great, which means potential loss is great. To illustrate this situation, this paper uses filtered historical simulation proposed by Barone-Adesi, G., K. Giannopoulos et al to measure the VaR of the two market conditions. Firstly, with two residual sequences, the bootstrap resampling can be used to simulate the future rate of return under the same initial state. Secondly, we set the asset holding time for 20 trading days, the daily number of simulations is 20,000 and the simulation results are as follows:
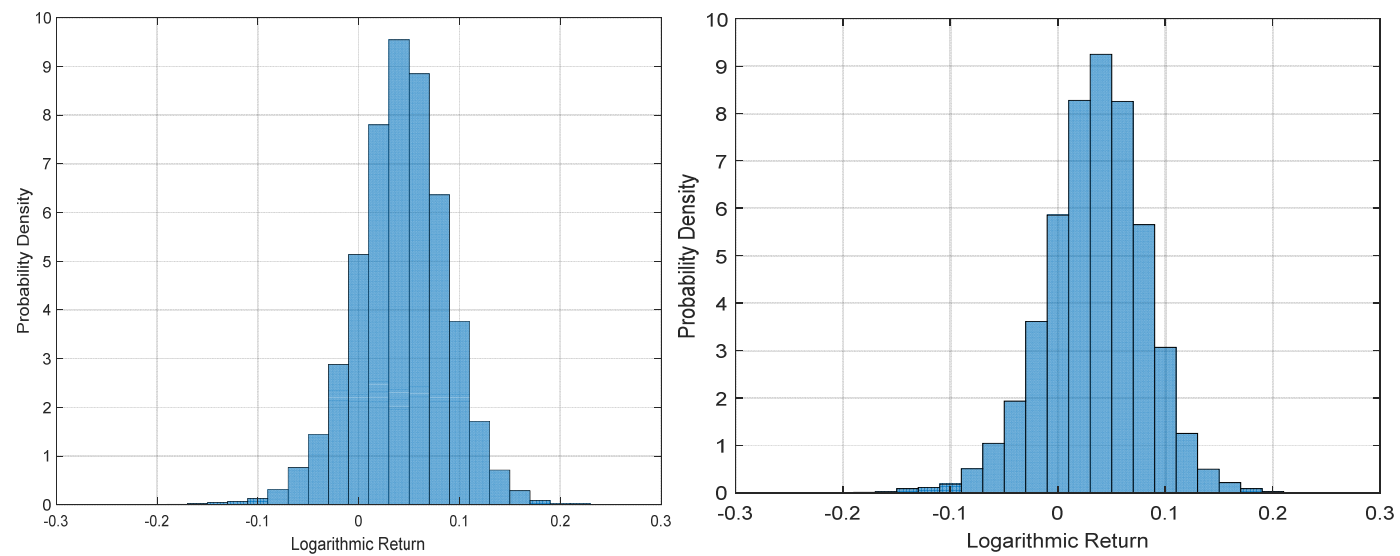

Figure 9. FHS simulation results before and after the introduction of margin trading

Table 5. Resampling simulation results

\begin{tabular}{cccccc}
\hline & $\begin{array}{c}\text { Maximum } \\
\text { possible loss }\end{array}$ & $\begin{array}{c}\text { Maximum } \\
\text { possible profit }\end{array}$ & $90 \% \mathrm{VaR}$ & $95 \% \mathrm{VaR}$ & $99 \% \mathrm{VaR}$ \\
\hline After & $31.79 \%$ & $24.50 \%$ & $-1.38 \%$ & $-3.30 \%$ & $-7.46 \%$ \\
Before & $25.00 \%$ & $21.99 \%$ & $-2.26 \%$ & $-4.27 \%$ & $-8.55 \%$ \\
\hline
\end{tabular}

Based on the above chart, we can find that in the condition of the stable market, margin trading do play a role of stabilizer in the market to some extent, but such influence is not significant. While in the volatile market with its conditions changed considerably, the risk of the margin trading is higher than before. It is concluded that the VaR at three different confidence interval after the introduction of margin trading are lower than those before. Moreover, under the extreme conditions of the market, the maximum loss after the margin trading is less than that before. To put it all into a nutshell, it reflects that the potential risks in the reforming process of China's securities market should be distinguished on a case by case basis. Policy makers are supposed to make a tradeoff between the benefits it offers and risks it poses.

\section{Conclusions and Policy Recommendations}

The introduction of margin trading is an inevitable choice when China's securities market develops to a certain level. As an important tool for performing the basic function of the stock market, margin trading is conducive to reducing market volatility in a certain way, but regulators cannot ignore the risk behind it. In this paper, GJR-GARCH is used to model the volatility of the CSI 300 index return series, and we measure the conditional variance sequence. Under the assumption that the series is subject to $t$ distribution, we measure the dynamic value of the risk before and after the introduction of the margin trading in a parametric way. The results shows that the established VaR calculation method can effectively measure the risk of the market. Then, based on the filter history simulation method with the help of the bootstrap resample technique, these two kinds of market environment are simulated by using the sampled residual sequence to obtain the $\mathrm{VaR}$, and the maximum possible loss and profit of the two market environments under the extreme conditions of the market are estimated. The main conclusions of this paper are as follows:

- After the introduction of margin trading, the market risk represented by the standard deviation decreased, and the market volatility declined significantly. And from the estimated parameters of the model, the market asymmetry, leverage after the launch had relatively declined, indicating that the policy has mitigated China's one-sided stock market condition. The appearance of the short mechanism reduces the asymmetry of the market to a certain degree.

- Based on the improved historical simulation, the value at risk under different confidence level also intimate the market volatility declined after the policy was made, but according to the results of the maximum and minimum loss, the subsequent effect is much greater than the previous one. Note that in the extreme market conditions, margin may worsen the market conditions.

Based on the above analysis, wepropose the following policy suggestions for regulators and financial institutions:

- Firstly, the regulatory authorities should reduce the excessive intervention in the market, and gradually open the door of margin trading to investors. As the underlying assets is relatively scarce, and the existence of transaction 
costs, the margin cannot make the best of its functions. Regulators should consider the applicability of specific types of stock trading rules and regulations to different kinds of assets, the underlying stock selection should be prudent to prevent market speculators from excessive speculation. At the same time, regulators should be able to control the risk, give the market some freedom to promote the development of financing and margin business, so that they can play a role in the balance of the market.

- Secondly, financial institutions should enhance risk management mechanisms and their standardize business processes. In order to implement the risk management task in all aspects of the transaction, the financial intermediaries need to limit its trading business within their risk tolerance level, and set margin ratio reasonably. Securities companies should also value the credit risk management procedure, and make a detailed investigation of investors' qualifications and credentials, improve investor education system, make them fully understand the potential risk of their investment, and not blindly follow the trend.

\section{References}

Adcock, C. J., Areal, N., \& Oliveira, B. (2012). Value-at-risk forecasting ability of filtered historical simulation for non-normal garch returns. Social Science Electronic Publishing. https://doi.org/10.2139/ssrn.2133238

Adesi, G. B., Giannopoulos, K., \& Vosper, L. (1999). Var without correlations for portfolios of derivative securities. Journal of Futures Markets, 19(5), 583-602. https://doi.org/10.1002/(SICI)1096-9934(199908)19:5<583::AID-FUT5>3.0.CO;2-S

Beber, A., \& Pagano, M. (2013). Short - selling bans around the world: evidence from the 2007-09 crisis. The Journal of Finance, 68(1), 343-381. https://doi.org/10.1111/j.1540-6261.2012.01802.x

Boehmer, E., \& Julie, W. (2010). Short selling and the informational efficiency of prices.

Bouyé, E., Durrleman, V., Nikeghbali, A., Riboulet, G., \& Roncalli, T. (2000). Copulas for finance - a reading guide and some applications. Social Science Electronic Publishing. https://doi.org/10.2139/ssrn.1032533

Charoenrook, A. A., \& Daouk, H. (2003). The world price of short selling. Social Science Electronic Publishing.

Detemple, J., \& Selden, L. (1991). A general equilibrium analysis of option and stock market interactions. International Economic Review, 32(2), 279-303. https://doi.org/10.2307/2526876

Feng, Y. M., Chen, X., \& Zhang, L. (2015). Research on the impact of margin trading on the volatility of China's stock market -- Based on the comparison test before and after the transfer of securities and loans. Shandong Social Sciences, (2), 130-134.

Gammoudi, I., El Ghourabi, M., \& Belkacem, L. (2016). Value-at-risk bounds for multivariate heavy tailed distribution: an application to the Glosten-Jagannathan-Runkle generalized autoregressive conditional heteroscedasticity model. The Journal of Risk Model Validation. https://doi.org/10.21314/JRMV.2016.157

Glosten, L. R., Jagannathan, R., \& Runkle, D. E. (1993). On the Relation between the Expected Value and the Volatility of the Nominal Excess Return on Stocks. The Journal of Finance, 48(5), 1779. https://doi.org/10.1111/j.1540-6261.1993.tb05128.x

Haruvy, E., \& Noussair, C. N. (2006). The effect of short selling on bubbles and crashes in experimental spot asset markets. The Journal of Finance, 61(3), 1119-1157. https://doi.org/10.1111/j.1540-6261.2006.00868.x

Jia, M. Q., \& Zhao, L. (2012). The effect of amplitude margin on the stock market. Accounting Monthly (9), 46-48.

Kang, Y. H., \& Liang, L. J. (2004). the VAR model based on GJR-GARCH and its empirical study in Shanghai stock market. Nankai management review, 7(4), 80-82.

McNeil, A. J., \& Frey, R. (2000). Estimation of tail-related risk measures for heteroscedastic financial time series: an extreme value approach. Journal of Empirical Finance, 7(3-4), 271-300. https://doi.org/10.1016/S0927-5398(00)00012-8

Miller, E. M. (1977). Risk, uncertainty, and divergence of opinion. The Journal of Finance, 32(4), 1151-1168. https://doi.org/10.1111/j.1540-6261.1977.tb03317.x

Nyström, K., \& Skoglund, J. (2005). Efficient filtering of financial time series and extreme value theory. The Journal of Risk, 7(2), 63-84. https://doi.org/10.21314/JOR.2005.107

Saffi, P. A. C., \& Sigurdsson, K. (2010). Price efficiency and short selling. Social Science Electronic Publishing, 24(3), 821-852.

Tang, Yan. (2012). VAR model analysis of margin and stock market volatility in China's stock market. Finance and Economics, (9), 17-20. 
Wang, M., Liao, S. G., \& Wu, S. K. (2008). The Study on the Impact Effects of Margin Trading on Stock Market: Evidence and Enlightenments from Taiwan Stock Market in China. Journal of Finance and Economics, 34(10), 99-109.

Wu-Yi, Y. E., Miao, B. Q., \& Zhen-Xiang, W. U. (2004). Bootstrap method based evaluating var. Journal of Systems Engineering.

Zhang, H. (2015). Empirical Research on VAR Model Based on GJR-GARCH, EVT and Copula. Science Journal of Applied Mathematics and Statistics, 3(3), 136. https://doi.org/10.11648/j.sjams.20150303.16

\section{Copyrights}

Copyright for this article is retained by the author(s), with first publication rights granted to the journal.

This is an open-access article distributed under the terms and conditions of the Creative Commons Attribution license which permits unrestricted use, distribution, and reproduction in any medium, provided the original work is properly cited. 